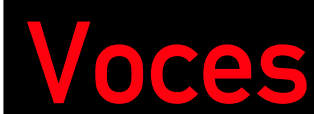

\section{Sombras Recobradas. Recuperación de un patrimonio}

José Briz y Pedro Joaquín del Rey

Presidente de honor y presidente de la AAFE

Sometido al inexorable desgaste del tiempo -de no remediarse, ape nas superará, en la mayoría de los casos, la barrera de un siglo- y de la humana incuria, el patrimonio cinematográfico, sobre todo aque de los primeros tiempos -el que alborea con el siglo XX, o lo que es lo mismo, las viejas películas, testimonios históricos, por añadidura, insuperables-, o ha desaparecido o sigue destruyéndose; se calcula que sólo se conserva alrededor de un diez por ciento del correspondiente a los años pioneros del cine, los que van hasta el decenio de los 30 del siglo pasado, cuya vigencia varía según los países.

Cabe alegar, no sin razón, que hoy conocemos la obra de creadores como Griffith, Murnau o Feuillade, lo cual resulta cierto de un modo general, pero no puede decirse que no resulte necesario continuar investigando, en particular a la hora de fijar, para cada filme, un acabado más o menos canónico de una reconstrucción que se pretenda lo más fiel posible a su forma original, a veces tarea dificilisima si tenemos en cuenta las insuficiencias técnicas en la producción y en el rodaje, que obligaban, al no contar entonces con la posibilidad de duplicar el negativo, a efectuar tomas diferenciadas para las distintas versiones iniciales en las que al final entraban las películas en los diferentes circuitos de exhibición de sus propias tierras de procedencia y de fuera de ellas. Lo antecedentemente señalado es un claro y significativo dato que refleja las muchas dificultades, en ocasiones prácticamente insalvables, que se dan para una cabal recuperación

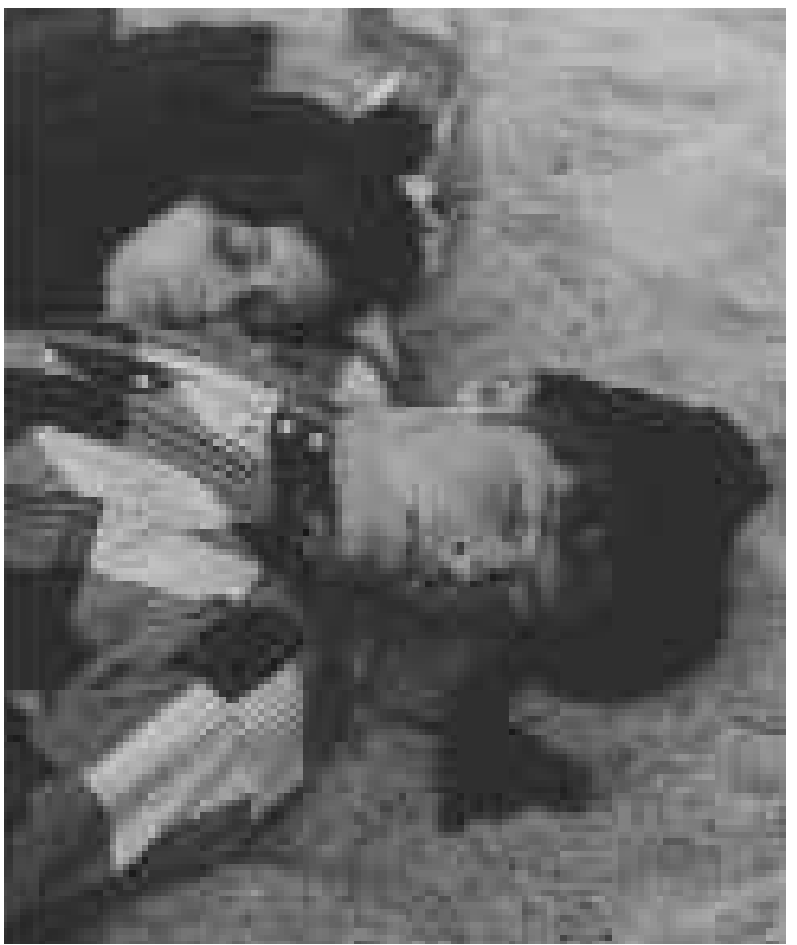

de tales singulares obras, a las que deben añadirse otras, normat mente fatales, como, por ejemplo, alteraciones en la emulsión o abarquillamientos en los soportes de nitrato.

Pero, además, hay que considerar que el conjunto del patrimonio cinematográfico supera al proveniente de unos pocos países o de determinados autores (aquí asimismo la mitomanía, harto letal para el cine, causa estragos), puesto que esta última circunstancia ha provocado, lamentablemente, el olvido, primero, y el abandono, después, de títulos y realizadores de gran valía, imprescindibles, como vamos comprobando, para completar una historia del cine al uso, que, día a día, se nos revela como insuficiente. Recientemente, en la muestra Sombras Recobradas 2005, los aficionados madrileños al buen cine han tenido la oportunidad de descubrir, con asombro, la existencia de un cine mudo portugués de calidad (definitivamente, el cine luso no sólo lo constituye Oliveira, director que en su larga trayectoria no fue ajeno al celuloide silente). Dos personalidades relevantes, dos cineastas de raza, Leitão de Barros (que, en 1944, reali zaría en España, junto a Manuel Augusto García Viñolas, Inés de Castro) y el misterioso trotamundos italiano Rino Lupo (que dirigió en Portugal siete filmes), y sus respectivas películas Maria do Mar y Os Lobos, primorosamente restauradas por la Cinemateca Portuguesa y dadas a conocer internacionalmente en L'Immagine Ritrovata, de Bolonia (Italia), y en Sombras Recobradas, se incorporan, con todo derecho y merecimiento, a la magra lista del patrimonio cinematográ fico recuperado. Recuperaciones lentas, prolijas y complejas, que frecuentemente exigen la voluntariosa cooperación de distintas entida des y filmotecas, pero, muy en especial, el amor y la devoción de aquellos que se entregan a una labor por la que escasos reconocimientos se pueden esperar.

Por la difusión y la recuperación del patrimonio cinematográfico nace Sombras Recobradas, una muestra organizada por la Asociación de Amigos de la Filmoteca Española (AAFE). En su segundo año, todavía en rodaje, la muestra se consolida por la calidad e interés de su programación (en esta edición se han exhibido varias reconstrucciones terminadas en el mismo 2005, como las portuguesas citadas, aparte de otras igualmente inéditas en España y que también fueron concluidas muy recientemente). Hay que hacer hincapié en que eventos similares a Sombras Recobradas son escasos en el mundo, apenas media docena, el más antiguo de ellos el que se celebra anualmente en Bolonia. Posiblemente, tal cortedad numérica en cuanto a este género de certámenes obedezca a que no nos encontramos frente a la típica clase de festival con premios, estrellas y oropeles. En Sombras Recobradas no hay nada más que cine.

La AAFE y Sombras Recobradas, en su lucha por la defensa, recuperación y divulgación del patrimonio cinematográfico, pretenden abordar directamente, en un futuro, la restauración y reconstrucción de películas. Es necesario, angustiosamente necesario, salvar tan extraordinario y vital patrimonio. 